\title{
Characterization and Taxonomic Significance of Lipopolysaccharides of Leptospira interrogans Serovar hardjo
}

\author{
By TU VINH,* MAN-HUA SHI, $\dagger$ BEN ADLER AND SOLLY FAINE \\ Department of Microbiology, Monash University, Clayton, Victoria 3168, Australia
}

(Received 14 March 1989; revised 23 June 1989; accepted 28 June 1989)

\begin{abstract}
Lipopolysaccharides (LPSs) from Leptospira interrogans serovar hardjo (reference strain hardjoprajitno and strain hardjobovis) were prepared by the hot phenol-water procedure. High yields of LPSs were found in the phenol phase. Gel electrophoresis of the phenol phase LPSs showed similar patterns for all strains in contrast to the different patterns found in the water phase LPSs. Sugar composition was also similar among all strains with rhamnose as the predominant sugar. Mannosamine was detected by high performance thin layer and gas-liquid chromatography. 2-Keto-3-deoxyoctonic acid (KDO) was comparable with authentic KDO by paper chromatography. Periodate oxidation at near neutral $\mathrm{pH}$ with or without prior hydrolysis showed that most of the KDO was substituted. The fatty acid composition of strain hardjobovis LPS was slightly different from that of the reference strain hardjoprajitno. Myristic and 3-hydroxymyristic acid were not detected in any of the LPS preparations. In conjunction with genetic and other data, the two strains are sufficiently different to be regarded as members of two separate species sharing common antigens. There is sufficient evidence to rename the hardjoprajitno strain type $L$. interrogans hardjo-p, and the hardjobovis strain type L. borgpeterseni hardjo- $b$.
\end{abstract}

\section{INTRODUCTION}

Leptospira interrogans serovar hardjo is a common causative agent of leptospirosis in Australia and New Zealand (Adler \& Faine, 1980; Blackmore \& Schollum, 1982) as well as in other parts of the world (White et al., 1981; Thiermann, 1984).

Leptospiral lipopolysaccharide (LPS) has been shown to be an important antigen capable of eliciting the production of protective antibody during infection (Adler \& Faine, 1978 a, $b$ ), thus playing an important role in leptospiral immunity (Jost et al., 1986; Chapman et al., 1988). Ultrastructurally, leptospiral LPS, consisting of ribbon-like structures, resembles the LPS of other Gram-negative bacteria (Vinh et al., 1986a). LPSs extracted from virulent strains of serovar copenhageni (Vinh et al., 1986a; Isogai et al., 1986) or serovar canicola Moulton strain (Shimizu et al., 1987a) lack hydroxytetradecanoic acid and 2-keto-3-deoxyoctonoic acid (KDO), characteristic components of Gram-negative, especially enterobacterial, LPS. However, a KDO-like component, giving a positive reaction with thiobarbituric acid, was found in these preparations (Vinh et al., 1986a; Shimizu et al., 1987a). Furthermore, these LPSs did not possess the endotoxic activity that is well-documented in the LPS of other Gram-negative bacteria (Finco \& Low, 1967; Vinh et al., 1986b; Isogai et al., 1986; Shimizu et al., 1987b).

Leptospires are classified by serology. The antigens involved are LPS components. At present a single species of pathogenic leptospires, $L$. interrogans, is recognized officially, based on agglutination-absorption tests (Kmety \& Dikken, 1988), but new species based on genetic differences have been proposed (Yasuda et al., 1987). The recognized type strain of serovar hardjo is hardjoprajitno (Wolff, 1953), but the prevalent infecting strain isolated from cattle and

† Present address: Department of Leptospirosis, Institute of Epidemiology and Microbiology, National Centre for Preventive Medicine, Beijing, People's Republic of China.

Abbreviation: KDO, 2-keto-3-deoxyoctonic acid (3-deoxy-D-manno-octulosonic acid). 
humans is hardjobovis (Robinson et al., 1982; Thiermann \& Ellis, 1986) which differs genetically (Lefebvre et al., 1987) but not serologically from hardjoprajitno. In this paper we have characterized and compared the LPS from hardjoprajitno and hardjobovis strains; the taxonomic significance of the findings for the two strains of serovar hardjo is also discussed.

\section{METHODS}

Leptospires. Leptospira interrogans serovar hardjo (reference strain hardjoprajitno, L13, and strain hardjobovis, L171 and L187) were used. Strain L171 was a New Zealand bovine isolate obtained from Dr R. Marshall, Massey University, New Zealand, typed by him as hardjobovis. Strain L187 was isolated from a human placenta in Australia (Faine et al., 1984); its characteristics resembled L171. The spirochaetes were grown and maintained as described previously (Vinh et al., 1984).

LPS extraction. Leptospiral LPSs were extracted by the hot phenol-water procedure of Westphal \& Jann (1965) as described previously (Vinh et al., 1986a). Because of the low yield of LPS in the water phase $(<1 \%$ total cell dry wt), LPS was extracted from the phenol phase as follows. The phenol phase was separated and dialysed extensively against tap-water at room temperature to completely remove the phenol, and was then dialysed against distilled water. The dialysed solution was then concentrated by ultrafiltration. An equal volume of absolute ethanol was added and the mixture was stirred overnight at $4{ }^{\circ} \mathrm{C}$ in the presence of $0.01 \%(w / v)$ sodium acetate. The precipitate formed was discarded and the supernate was brought to $90 \%(\mathrm{v} / \mathrm{v})$ ethanol. The mixture was again stirred overnight at $4{ }^{\circ} \mathrm{C}$ in the presence of $0.01 \%(\mathrm{w} / \mathrm{v})$ sodium acetate. The precipitate was collected and purified by ultracentrifugation as described previously (Vinh et al., 1986a). Samples of LPS in double-glass-distilled water $\left(100 \mu \mathrm{g} \mathrm{m}^{-1}\right)$ were examined by UV absorption spectrophotometry to detect the presence of nucleic acids and proteins.

Escherichia coli O127 : B8 LPS was purchased from Difco and Salmonella minnesota LPS from Sigma.

$S D S-P A G E$. Samples of LPS preparations $(10 \mu \mathrm{g})$ were electrophoresed (Laemmli, 1970) using a $1 \mathrm{~mm}$ thick slab gel in a Bio-Rad Protean II gel apparatus. A $15 \%$ (w/v, acrylamide) separating gel and a $5 \%$ stacking gel without SDS (Hitchcock \& Brown, 1983) were used and electrophoresis was done as described previously (Jost et al., 1988). Proteinase-digested whole cell lysates were prepared as described by Hitchcock \& Brown (1983). LPS bands were detected by the silver staining technique (Tsai \& Frasch, 1982) as modified by Hitchcock \& Brown (1983) with a minor modification in the developer solution whereby a concentration of $0 \cdot 25 \%(w / v)$ of citric acid was used instead of $0.05 \%(w / v)$. The increase in citric acid concentration was found to circumvent the overdevelopment of the bands, thus giving better control of colour development.

Production of monoclonal antibodies. The production of monoclonal antibodies against Leptospira interrogans serovar hardjo LPS was described previously (Farrelly et al., 1987).

Immunogold labelling. For immune electron microscopy cultures $(5 \mathrm{ml})$ of leptospires in late exponential phase were used. After centrifugation for $10 \mathrm{~min}$ at $8000 \mathrm{~g}$ at room temperature, the leptospiral pellet was washed with tissue culture medium 199 (M199) containing 15 mM-HEPES without foetal calf serum, and resuspended in the same medium $(0.5 \mathrm{ml})$. A drop of leptospiral suspension was deposited onto a carbon-Formvar-coated, 400-mesh copper grid for $20 \mathrm{~min}$ at room temperature. Excess fluid was removed with filter paper. The grids were then inverted onto a drop of a $1 \%(w / v)$ solution of bovine serum albumin (BSA) in M199 at room temperature for $20 \mathrm{~min}$ to prevent non-specific binding. After removal of excess fluid the grids were inverted onto a drop of either monoclonal antibody (MUM/F1-4/hardjo) dilution or Dulbecco's Modified Medium (control) for $1 \mathrm{~h}$ at $30^{\circ} \mathrm{C}$. Excess fluid was removed and the grids were washed with M199 containing $1 \%(w / v)$ BSA. The grids were then incubated with goat anti-mouse immunoglobulin colloidal gold conjugate (Auroprobe EM GAMIgG + IgM G5; Jannsen) for $30 \mathrm{~min}$ at room temperature. The grids were washed with M199 containing $1 \%$ (w/v) BSA, then with distilled water and stained with an aqueous solution of $2 \%(\mathrm{w} / \mathrm{v})$ ammonium molybdate. After air drying, the grids were examined with a JEOL 100 electron microscope at $60 \mathrm{kV}$.

Chemical analyses. Protein was measured by the micromethod of Bradford (1976) using Bio-Rad protein assay reagents. Total carbohydrate was determined by the phenol/sulphuric acid method (Dubois et al., 1956) using glucose as standard. Heptose and hexosamines were determined according to methods described by Nowotny (1979). Phosphorus was determined according to Chen et al. (1956). 2-Keto-3-deoxyoctonic acid (KDO) was estimated by the thiobarbituric acid reaction described by Karkhanis et al. (1978) after hydrolysis of LPSs either with $0 \cdot 1 \mathrm{M}-\mathrm{H}_{2} \mathrm{SO}_{4}$ at $100{ }^{\circ} \mathrm{C}$ for $20 \mathrm{~min}$ or $4 \mathrm{M}-\mathrm{HCl}$ at $100^{\circ} \mathrm{C}$ for $1 \mathrm{~h}$. Commercial $\mathrm{KDO}$ (Sigma) was used as a standard.

Determination of KDO without prior hydrolysis (Drogue et al., 1970). To $50 \mu \mathrm{g}$ LPS in $50 \mu \mathrm{l}$ water were added $20 \mu \mathrm{l}$ $25 \mathrm{~mm}$-sodium periodate and the tube kept in the dark at $4{ }^{\circ} \mathrm{C}$ overnight. Sodium arsenite $(20 \mu \mathrm{l} ; 0.2 \mathrm{M})$ in $0.5 \mathrm{M}-\mathrm{HCl}$ was added to stop the oxidation. After complete reduction of periodate $410 \mu \mathrm{l}$ water was added and the tubes were heated in a boiling water-bath for $15 \mathrm{~min}$ and cooled in iced water. The reaction was then continued as described above.

Gas-liquid chromatography (GLC). To prepare samples for GLC analysis of fatty acids and monosaccharides, $1 \mathrm{mg}$ of each LPS was hydrolysed with $4 \mathrm{M}-\mathrm{HCl}$ for $1 \mathrm{~h}$ at $100^{\circ} \mathrm{C}$. The fatty acids were extracted with 
chloroform/methanol $(1: 1, \mathrm{v} / \mathrm{v})$, dried with a stream of dry nitrogen and methylated as described previously (Vinh et al., 1986a). The solution containing monosaccharides was dried in vacuo in the presence of $\mathrm{KOH}$.

Fatty acid methyl esters were dissolved in $50 \mu \mathrm{l}$ high purity grade hexane (Hipersolv; BDH) and $1 \mu \mathrm{l}$ was injected into a Varian 3700 gas-liquid chromatograph equipped with a 25QC2/BP10 0.25 mm capillary column (SGE) and a flame ionization detector. The injector was operated with a 1:60 split ratio. Nitrogen was used a carrier gas at a rate of $30 \mathrm{ml} \mathrm{min}{ }^{-1}$. The injector and detector temperatures were $230^{\circ} \mathrm{C}$ and $300{ }^{\circ} \mathrm{C}$ respectively. The temperature was programmed from 120 to $270{ }^{\circ} \mathrm{C}$ at a rate of $8{ }^{\circ} \mathrm{C} \mathrm{min}{ }^{-1}$. The fatty acid profile was recorded with a Spectra Physics model SP4270 integrator and fatty acids were identified by comparison with known standards (Bacterial fatty acid methyl esters: Supelco).

Trimethyisilyl derivatives of monosaccharides were prepared by adding $100 \mu \mathrm{l}$ TriSil (Pierce Chemicals). The mixture was incubated at $60^{\circ} \mathrm{C}$ for $30 \mathrm{~min}$ and then samples $(1 \mu \mathrm{l})$ were injected into a gas-liquid chromatograph as described above except that the injector was operated at a $1: 35$ split ratio and the temperature program started at $160^{\circ} \mathrm{C}$ for $4 \mathrm{~min}$, increasing to a maximum temperature of $260^{\circ} \mathrm{C}$ at a rate of $5{ }^{\circ} \mathrm{C} \mathrm{min}{ }^{-1}$. The sugars were identified by comparison with known standard sugars. To detect amino sugars, the alditol acetate derivatization method of Blakeney et al. (1983) was used.

Paper chromatography. KDO was identified by ascending paper chromatography using Whatman no. 1 filter paper with ethyl acetate/pyridine/water $(2: 1: 2$, by vol.) as solvent. The spots were detected with the thiobarbiturate reagent described by Nowotny (1979).

Detection of mannosamine by high-performance thin-layer chromatography (HPTLC). Monosaccharide hydrolysate $(0.5 \mu \mathrm{l}$, prepared as above) was applied to $5 \times 7 \mathrm{~cm}$ aluminium-backed Merck Kieselgel 60 F254 HPTLC plates $1 \mathrm{~cm}$ from the bottom edge. The separation was done as described by Rebers $e t$ al. (1986) using acetonitrile/acetic acid/ethanol/water $(13: 1: 2: 4$, by vol.) as the solvent system. D-Glucosamine, D-galactosamine and D-mannosamine (Sigma) were used as reference compounds. After separation, the plates were dipped in $0 \cdot 2 \%$ $(\mathrm{w} / \mathrm{v})$ ninhydrin in ethanol followed by heating at $100^{\circ} \mathrm{C}$ to locate amino sugars. Solutions of silver nitrate in acetone and sodium hydroxide in ethanol (Stahl, 1969) were also used to detect reducing sugars.

\section{RESULTS}

\section{LPS extraction}

Leptospiral LPSs of serovar hardjo were found in both water and phenol phases when extracted by the phenol-water procedure of Westphal \& Jann (1965). The yield of LPS in the water phase was very low $(<1 \%$ cell dry wt). In contrast, the yield of LPS in the phenol phase accounted for 5-7\% cell dry wt for all three strains. All LPS preparations were checked by UV absorption. The main leptospiral LPS peak was located at $192 \mathrm{~nm}$ as described previously (Vinh et al., 1986a). No absorption peaks corresponding to nucleic acids or proteins were detected at $260 \mathrm{~nm}$ and $280 \mathrm{~nm}$ respectively. Serovar hardjo LPS from either phase had a ribbon-like ultrastructure observed by electron microscopy (data not shown) as described previously for serovar copenhageni (Vinh et al., 1986a).

\section{$S D S-P A G E$}

The silver-stained gel profiles of all LPS preparations are shown in Fig. 1. Unlike the ladderlike profile of smooth-type enterobacterial LPSs (lanes 1 and 2), LPSs extracted from L. interrogans serovar hardjo showed different patterns on polyacrylamide gels. LPSs obtained from the phenol phase had similar patterns for all three strains (lanes 6,7 and 8), whereas those obtained from the water phase showed different profiles between strain hardjoprajitno (lane 5) and the other two hardjobovis strains (lanes 3 and 4), both of which were similar. The phenol phase LPSs of all three strains and the water phase LPS of strain hardjoprajitno possessed three main characteristic and diffuse bands located between 18 and $30 \mathrm{kDa}$, whereas one main band at $28 \mathrm{kDa}$ was found in the water phase LPSs of the two hardjobovis strains. A lower molecular mass band located in the region of the 'core-lipid A' of smooth Gram-negative bacterial LPSs (lanes 1 and 2, Fig. 1) was present in all LPSs; however it was much less intense in the water phase LPSs. The silver-stained profile of purified LPS was similar to that of the proteinase-Kdigested whole cell lysate (data not shown). When transblotted and immunostained with a monoclonal antibody MUM/F1-4/hardjo, the three main bands described above were found to be reactive as described previously (Farrelly et al., 1987) for all LPS preparations (data not shown). However, the monoclonal antibody did not react with the low molecular mass 'corelipid A' band. 


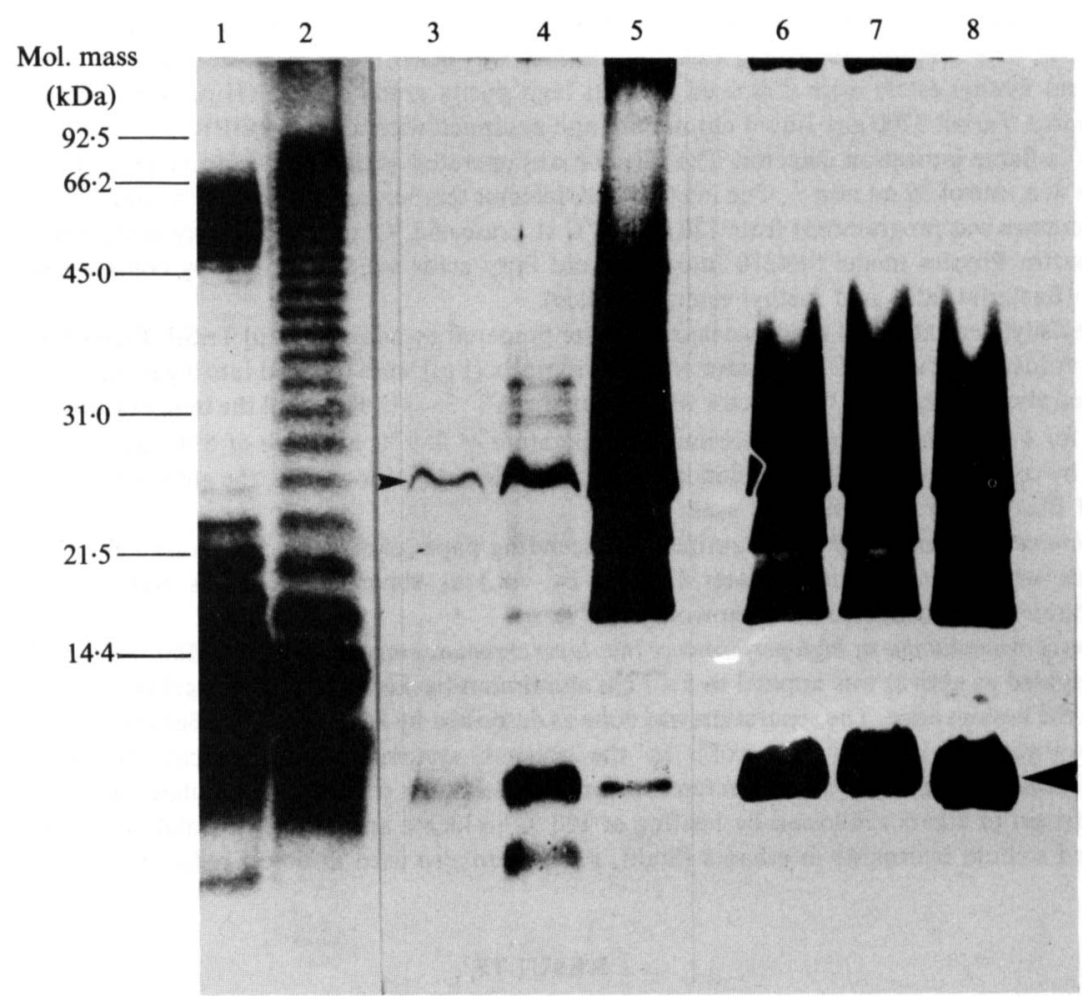

Fig. 1. Silver-stained SDS-PAGE profile of aqueous and phenol phase LPS preparations. Lane 1, E. coli O127 : B8 LPS; lane 2, Salmonella minnesota LPS; lanes 3, 4 and 5, aqueous phase LPSs of serovar hardjo, hardjobovis strains L171 (lane 3), L187 (lane 4) and hardjoprajitno strain L13 (lane 5); lanes 6, 7 and 8, phenol phase LPSs of hardjobovis strains L171 (lane 6), L187 (lane 7) and hardjoprajitno strain L13 (lane 8). The small arrowhead $(\rightarrow$ ) indicates the $28 \mathrm{kDa}$ band and the big arrowhead ( $>$ ) indicates the band corresponding to the 'core-lipid A' region of Gram-negative LPS.

Table 1. Composition of LPSs of L. interrogans serovar hardjo

Values are means of two determinations \pm SE. ND, Not determined.

\begin{tabular}{|c|c|c|c|c|}
\hline \multirow[b]{3}{*}{ Component } & \multicolumn{4}{|c|}{ Amount present $\left[\mu \mathrm{g}(\mathrm{mg} \mathrm{LPS})^{-1}\right]$} \\
\hline & \multirow{2}{*}{$\begin{array}{c}\text { hardjoprajitno } \\
\text { L13 }\end{array}$} & \multicolumn{2}{|c|}{ hardjobovis } & \multirow{2}{*}{$\begin{array}{c}\text { E. coli } \\
\text { O127:B8 }\end{array}$} \\
\hline & & L171 & L187 & \\
\hline Protein & $58 \pm 5 \cdot 0$ & $36 \pm 1.0$ & $35 \pm 1 \cdot 0$ & $58 \pm 5 \cdot 0$ \\
\hline Lipid & $350 \pm 10 \cdot 0$ & $420 \pm 8 \cdot 0$ & $370 \pm 15 \cdot 0$ & $290 \pm 10 \cdot 0$ \\
\hline Total carbohydrate & $290 \pm 10 \cdot 0$ & $292 \pm 10 \cdot 0$ & $300 \pm 15 \cdot 0$ & $175 \pm 5.0$ \\
\hline Amino sugars & $60 \pm 5 \cdot 0$ & $54 \pm 5.0$ & $54 \pm 5 \cdot 0$ & ND \\
\hline Heptose & $7 \pm 0.1$ & $8 \cdot 5 \pm 0 \cdot 3$ & $8 \pm 0.1$ & ND \\
\hline KDO & $8 \pm 0.5$ & $12 \pm 1.0$ & $12.5 \pm 1.0$ & $14 \pm 1 \cdot 0$ \\
\hline Phosphorus & $8 \pm 0.5$ & $10 \pm 1 \cdot 0$ & $9 \pm 0.5$ & $\mathrm{ND}$ \\
\hline
\end{tabular}

Immunogold labelling. Immunogold staining of serovar hardjo (strain hardjoprajitno) with anti-LPS monoclonal antibody MUM/F1-4/hardjo showed that gold particles attached both to the surface of the leptospire as well as to LPS which had apparently detached from the leptospiral cell (Fig. 2).

Chemical analyses. Because of the low yield of water phase LPSs, all chemical analyses were done on phenol phase LPSs which were shown to have similar profiles on silver-stained SDSPAGE gels. 

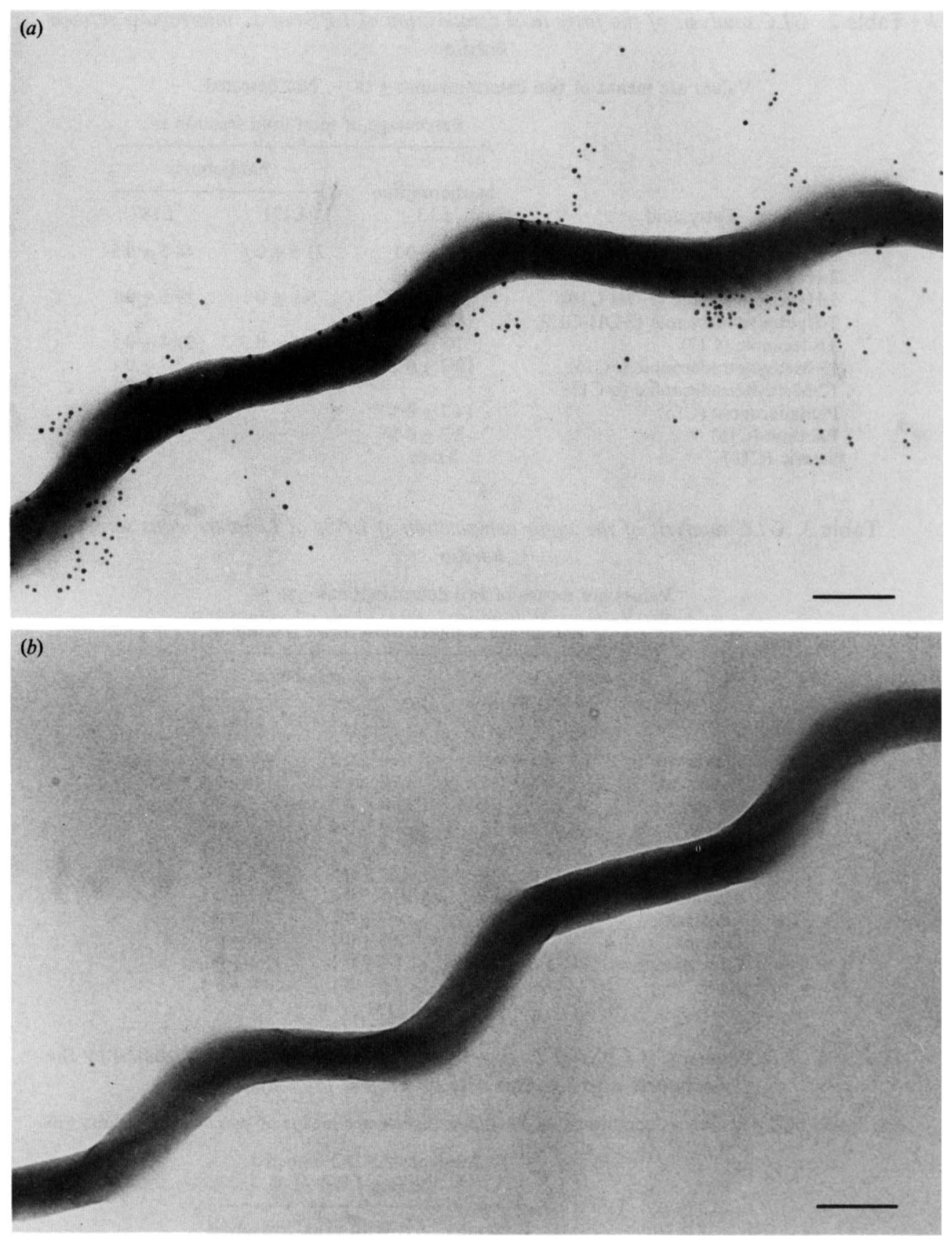

Fig. 2. (a) Immunogold labelling of serovar hardjo, strain hardjoprajitno L13, with MUM/F1-4/hardjo anti-LPS monoclonal antibody. $(b)$ Control. Bars, $1 \mu \mathrm{m}$.

The general composition of serovar hardjo LPS is shown in Table 1, and the fatty acid composition is shown in Table 2 . Branched fatty acids $(a, i-\mathrm{C} 15)$, decanoic $(\mathrm{C} 10)$ and tridecanoic (C13) acids were found in all the LPS samples. LPS of strains L171 and L187 contained similar fatty acids including 3-hydroxy-decanoic acid (3-OH-C10), whereas strain L13 (hardjoprajitno) LPS contained different fatty acids including 2-hydroxydecanoic (2-OH-C10), 2-hydroxydodecanoic (2-OH-C12), palmitic and stearic acids. Myristic and hydroxymyristic acids were not detected in any of the LPS samples. 
Table 2. GLC analysis of the fatty acid composition of LPSs of L. interrogans serovar hardjo

Values are means of two determinations \pm SE. - , Not detected.

Percentage of total lipid fraction in:

Fatty acid

Decanoic (C10)

2-Hydroxydecanoic (2-OH-C10)

3-Hydroxydecanoic (3-OH-C10)

2-Hydroxydodecanoic (2-OH-C12)

Tridecanoic (C13)

13-Methyltetradecanoic (i-C15)

12-Methyltetradecanoic ( $a$-C15)

Pentadecanoic (C15)

Palmitic (C16)

Stearic (C18)

$\overbrace{\substack{\text { hardjoprajitno } \\ \text { L13 }}}^{\text {hardjobovis }}$

$\begin{array}{rcc}29.4 \pm 0.1 & 21.5 \pm 0.1 & 48.5 \pm 0.5 \\ 12.8 \pm 1 \cdot 0 & - & - \\ - & 9.5 \pm 0.1 & 19.5 \pm 0.1 \\ 18.4 \pm 1 \cdot 2 & - & - \\ 7.3 \pm 0.1 & 23.7 \pm 0.5 & 21 \cdot 4 \pm 0.5 \\ 10.2 \pm 0.2 & 9.4 \pm 0.1 & 3.7 \pm 0.1 \\ - & 6.7 \pm 0.1 & 4.2 \pm 0.1 \\ 14.7 \pm 0.5 & - & - \\ 3.2 \pm 0.1 & - & - \\ \text { Trace } & - & -\end{array}$

Table 3. GLC analysis of the sugar composition of LPSs of L. interrogans serovar hardjo

Values are means of two determinations $\pm \mathrm{SE}$.

Percentage of total carbohydrate fraction in:

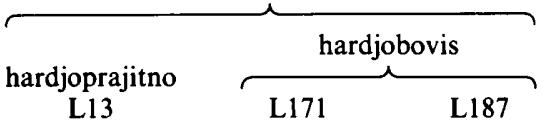

\begin{tabular}{|c|c|c|c|}
\hline Unknown & $4 \cdot 5 \pm 0 \cdot 5$ & $5.0 \pm 0.2$ & $4.8 \pm 0.2$ \\
\hline Arabinose & $10.5 \pm 0.5$ & $13.7 \pm 1.0$ & $11.0 \pm 1.0$ \\
\hline Rhamnose & $22 \cdot 0 \pm 1 \cdot 0$ & $25 \cdot 0 \pm 0.8$ & $24.8 \pm 0.6$ \\
\hline Ribose & $15 \cdot 0 \pm 0.5$ & $7.4 \pm 0.9$ & $10 \cdot 8 \pm 0.4$ \\
\hline Fucose & $2 \cdot 4 \pm 0 \cdot 1$ & $2 \cdot 5 \pm 0 \cdot 1$ & $1 \cdot 2 \pm 0 \cdot 1$ \\
\hline Xylose & $15 \cdot 6 \pm 0 \cdot 1$ & $17 \cdot 7 \pm 0.5$ & $19 \cdot 5 \pm 1 \cdot 2$ \\
\hline Mannose & $8 \cdot 1 \pm 0.1$ & $10 \cdot 5 \pm 0 \cdot 3$ & $9 \cdot 3 \pm 0 \cdot 1$ \\
\hline Galactose & $1 \cdot 2 \pm 0 \cdot 0$ & $6 \cdot 7 \pm 0 \cdot 1$ & $3.5 \pm 0.1$ \\
\hline Glucose & $3 \cdot 1 \pm 0 \cdot 1$ & $3.0 \pm 0.5$ & $3 \cdot 5 \pm 0.6$ \\
\hline Glucosamine & $1.6 \pm 0.0$ & $1.5 \pm 0.1$ & $2 \cdot 4 \pm 0.0$ \\
\hline KDO & $1 \cdot 1 \pm 0 \cdot 3$ & $1.5 \pm 0.1$ & $0.9 \pm 0.1$ \\
\hline
\end{tabular}

Table 4. KDO content of LPSs of L. interrogans serovar hardjo as determined by the thiobarbituric acid reaction with or without prior hydrolysis

For details of the hydrolysis conditions see Methods. Values are means of two determinations \pm SE.

\begin{tabular}{|c|c|c|c|}
\hline \multirow[b]{3}{*}{ Source of LPS } & \multicolumn{3}{|c|}{$\begin{array}{l}\text { Amount of KDO detected } \\
{\left[\mu \mathrm{g}(\mathrm{mg} \mathrm{LPS})^{-1}\right]}\end{array}$} \\
\hline & \multirow{2}{*}{$\begin{array}{l}\text { Without } \\
\text { prior } \\
\text { hydrolysis }\end{array}$} & \multicolumn{2}{|c|}{ With prior hydrolysis } \\
\hline & & Mild & Strong \\
\hline hardjoprajitno L13 & $10 \cdot 0 \pm 1 \cdot 0$ & $9 \cdot 0 \pm 0 \cdot 5$ & $55 \cdot 0 \pm 5 \cdot 0$ \\
\hline hardjobovis L171 & $12 \cdot 0 \pm 1 \cdot 0$ & $12 \cdot 5 \pm 1 \cdot 0$ & $40 \cdot 0 \pm 5 \cdot 0$ \\
\hline hardjobovis L187 & $12 \cdot 5 \pm 1 \cdot 0$ & $13 \cdot 0 \pm 1 \cdot 0$ & $65 \cdot 0 \pm 6 \cdot 0$ \\
\hline
\end{tabular}

The sugar composition is shown in Table 3. All LPSs contained a similar number of monosaccharides. The major component was rhamnose, representing $20 \%(\mathrm{w} / \mathrm{v})$ of the total monosaccharides. By using HPTLC for amino sugar analysis a spot having the same $R_{F}$ as that of the mannosamine standard was detected. This component was identified as an amino sugar 
by reaction with ninhydrin as well as with silver nitrate. This was confirmed by GLC of alditol acetate derivatives, when a peak having the same retention time as D-mannosaminitol was detected.

As shown in Table 4 the amount of KDO detected in all the LPSs increased considerably when the LPS samples were subjected to strong acid hydrolysis $\left(4 \mathrm{M}-\mathrm{HCl}\right.$ at $100{ }^{\circ} \mathrm{C}$ for $\left.1 \mathrm{~h}\right)$, indicating the presence of substituted KDO. To confirm this observation, the procedure of Drogue et al. (1970), using periodate oxidation at $\mathrm{pH}$ 5-6 with or without prior hydrolysis, was followed. The results (Table 4) showed that with periodate oxidation of LPSs prior to hydrolysis only 6-12 $\mu \mathrm{g}$ (unsubstituted) KDO (mg LPS) ${ }^{-1}$ were detected, whereas the amount of KDO detected increased up to $40-65 \mu \mathrm{g}$ (mg LPS $)^{-1}$ after hydrolysis, indicating that most of the KDO in serovar hardjo LPS was substituted at position C4 and/or C5.

Paper chromatography of KDO from LPSs of serovar hardjo revealed that this compound had the same mobility as that of authentic KDO $\left(R_{F} 0 \cdot 30\right)$.

\section{DISCUSSION}

The present study describes the composition and gel profiles of LPSs extracted from Leptospira interrogans serovar hardjo, strain hardjoprajitno, which is the standard reference laboratory strain, and two local field isolate hardjobovis strains by the hot phenol-water procedure of Westphal \& Jann (1965). LPSs of serovar hardjo were found in both aqueous and phenol phases. However, very little LPS could be obtained from the aqueous phase. One possible reason for this may be that the content of lipid in serovar hardjo LPS is higher ( $\geqslant 30 \%$, Table 1$)$ than that of water-soluble E. coli LPS (Table 1), thus rendering the leptospiral LPS less soluble in water; hence it partitions preferentially into the phenol phase. It has been suggested that the solubility of the LPS molecule is dependent on the relative proportion of the hydrophilic polysaccharide and the hydrophobic lipid A (Galanos \& Luderitz, 1984). The LPS of certain other bacteria has also been found in both phases (Raff \& Wheat, 1968; Kreutzer et al., 1979; Jessop et al., 1988). LPS of other leptospiral serovars (copenhageni, pomona) is also found in the water phase. Clearly hardjo is different. On the other hand the original LPS-like TM antigen of serovar kremastos (Shinagawa \& Yanagawa, 1972) was prepared from the phenol phase. The phase partitioning properties may vary between serovars and not be related to serovar specificity.

Structurally, the LPS preparations showed ribbon-like forms similar to that described previously for serovar copenhageni (Vinh et al., 1986a). When examined by immunogold staining with a specific monoclonal antibody, LPS appeared to be distributed homogeneously on the outer membrane of the leptospire as shown by the binding of gold particles.

The different silver-stained gel profiles of the aqueous phase LPSs of the hardjobovis strains and the reference strain hardjoprajitno could be useful in distinguishing these two subtypes. In addition, our results indicate that it is inappropriate to rely solely upon standard water phase LPS in comparing profiles (Cinco et al., 1986).

The general chemical composition was similar in all three strains of serovar hardjo LPSs which have a lipid content (35-40\%) higher than that of serovar copenhageni LPS (33\%) (Vinh et al., 1986a) and E. coli O127:B8 LPS ( $29 \%$ ).

The fatty acid composition of the reference hardjoprajitno and hardjobovis strains was somewhat different in that palmitic acid $(\mathrm{C} 16: 0)$ and stearic acid $(\mathrm{C} 18: 0)$ were not present in the hardjobovis strains. On the other hand, all LPSs possessed a fatty acid identified as isobranched pentadecanoic acid $(i-\mathrm{C} 15: 0)$. Branched chain fatty acids have been found generally in Gram-positive bacteria and in some Gram-negative bacteria (Jantzen \& Bryn, 1985; Wollenweber et al., 1980). Isobranched fatty acids were shown to be present in the LPSs of Pseudomonas species (Moss et al., 1973; Wilkinson et al., 1973). Whether or not the presence of this branched chain fatty acid in serovar hardjo LPSs has any taxonomic significance cannot yet be established.

The sugar composition of LPSs from serovar hardjo was similar to that previously reported in the LPS extracted from serovar copenhageni (Vinh et al., 1986a) with a high content of rhamnose. The presence of mannosamine detected by HPTLC and by GLC as alditol acetate derivatives is the first reported for leptospiral LPS. Mannosamine could not be detected as 
a trimethylsilyl derivative because it was insoluble in the trimethylsilyl derivatizing reagent thus masking its detection by GLC. Although we did not quantify the amount of mannosamine in LPS it appears that mannosamine was a major amino sugar in leptospiral LPS. Mannosamine has been found in the LPS of Salmonella groups $\mathrm{J}$ and T, E. coli O31 and Arizona 15 (Luderitz et al., 1968), in the polysaccharide of pneumococcus type XIX (Shabarova et al., 1962), and recently of group E Streptococcus strain K131 (Rebers et al., 1986). The presence of mannosamine and other amino sugars in the LPS of other leptospiral strains is currently under investigation.

Unlike the KDO-like sugar detected in the LPS of serovar copenhageni, KDO in the LPSs of serovar hardjo was found to have the same mobility as that of the authentic KDO on ascending paper chromatography. The amount of KDO estimated by the thiobarbituric acid reaction after mild acid hydrolysis was 6-12 $\mu \mathrm{g}$ (mg LPS) ${ }^{-1}$. However, when the strength of acid for hydrolysis of LPSs was increased to $4 \mathrm{M}-\mathrm{HCl}$ the amount of KDO detectable increased considerably [40$65 \mu \mathrm{g}$ (mg LPS $^{-1}$ ]. The small amount of KDO detected after mild acid hydrolysis may be due to the substitution at positions $\mathrm{C} 4$ and/or $\mathrm{C} 5$, thus requiring strong acid hydrolysis conditions to break the linkages of these substituents (Brade et al., 1983; Zamze \& Moxon, 1987). This was confirmed by periodate oxidation at near neutral $\mathrm{pH}$ with or without prior hydrolysis of LPS (Drogue et al., 1970). The results showed that only a small amount of KDO which was not substituted at positions $\mathrm{C} 4$ and $\mathrm{C} 5$ was detected without prior hydrolysis, suggesting that most of the KDO was substituted at these positions. Substituted KDO has been shown to react weakly or not at all with thiobarbituric acid (Drogue et al., 1970; Charon \& Szabo, 1972; Chaby \& Szabo, 1975). The apparent absence of authentic KDO in LPS from some leptospiral strains (Vinh et al., 1986a; Isogai et al., 1986; Shimizu et al., 1987a) has prompted some workers to suggest that leptospires do not possess typical Gram-negative LPS (Shimizu et al., 1987a). Recently, Cinco et al. (1988) found only traces of fatty acids in the phenol-water extract from $L$. interrogans serovar copenhageni (strain Teramo), and concluded that LPS was not present in L. interrogans. However, our present results with serovar hardjo indicate that leptospiral LPS is structurally and biochemically very similar to classical Gram-negative LPS.

Although there were physicochemical differences between the LPSs of hardjoprajitno and bovis, they are antigenically very similar (Farrelly et al., 1987) and only minor epitope differences have been detected using monoclonal antibodies. The two strains are indistinguishable on the basis of agglutinating absorption tests (Kemety \& Dikken, 1988) which measure mainly, if not exclusively, LPS antigens. This is consistent with the almost identical monosaccharide composition of the three strains, and with the carbohydrate nature of the agglutinating epitopes in Leptospira (Jost et al., 1986; Terpstra et al., 1987; Farrelly et al., 1987). Both hardjoprajitno and hardjobovis share major epitopes involved in diagnosis, classification and possibly immunity, and both have a high lipid content which may be responsible for their LPS partitioning mainly in the phenol phase. However, the two strains show significant differences on PAGE of their aqueous phase LPS, and are genetically different. It has been shown that these two strains can be identified separately by restriction endonuclease DNA analysis (Robinson et al., 1982; Thiermann et al., 1986) and DNA hybridization and G+C content (Lefebvre \& Thiermann, 1986; Lefebvre et al., 1987). The hardjoprajitno strain has a $\mathrm{G}+\mathrm{C}$ content of $34.9 \mathrm{~mol} \%$ (Lefebvre et al., 1987; Yasuda et al., 1987) which would place it in the proposed new interrogans species, while hardjobovis has a $G+C$ content of $39.9 \mathrm{~mol} \%$, consistent with the proposed species borgpeterseni (Yasuda et al., 1987). These results give good reason to divide the current $L$. interrogans serovar hardjo into two different species, new species $L$. interrogans serovar hardjo, which is the hardjoprajitno strain and new species $L$. borgpeterseni serovar hardjo which is the hardjobovis strain.

The use of the infrasubspecific nomenclature for the strain types 'hardjoprajitno' and 'hardjobovis' is cumbersome and impractical, especially since serology by agglutination or ELISA with whole organisms or fragments or LPS cannot distinguish between them. DNA probes or gel profiles of aqueous phase LPS can, but are not readily available. For practical purposes of identification and nomenclature, the use for the time being of the trinomials $L$. interrogans hardjo- $p$ for the strains of the hardjoprajitno type, and $L$. borgpeterseni hardjo- $b$ for 
the hardjobovis type is recommended. They cannot be referred to legitimately as different serovars because they are not serologically different according to the rules of leptospiral taxonomy (Faine, 1982).

The presence of substituted KDO requires the use of strong acid hydrolysis to obtain an accurate measurement of $\mathrm{KDO}$, and mannosamine is a constituent of leptospiral LPS.

This work was supported by a research grant from the National Health and Medical Research Council, Canberra, Australia. We thank Khim Hoe for her excellent assistance in immuno-electronmicroscopic technique.

\section{REFERENCES}

AdLER, B. \& FAINE, S. (1978a). The antibodies involved in the human immune response to leptospiral infection. Journal of Medical Microbiology 11, $387-400$.

ADLER, B. \& FAINE, S. (1978b). Serological and protective antibody responses of rabbits to leptospiral antigens. Journal of Medical Microbiology 11, 401-409.

ADLER, B. \& FAINE, S. (1980). Epidemiology of human leptospirosis in Australia. Communicable Diseases Intelligence (Australian Department of Health) $80 / 21,2-5$

Blackmore, D. K. \& Schollum, L. (1982). Risks of contracting leptospirosis on the dairy farm. New Zealand Medical Journal 95, 649-652.

Blakeney, A. B., HaRris, P. J., HenRy, R. J. \& Stone, B. A. (1983). A simple and rapid preparation of alditol acetates for monosaccharide analysis. Carbohydrate Research 113, 291-299.

Brade, H., Galanos, C. \& Luderitz, O. (1983). Differential determination of the 3-deoxy-D-mannooctulosonic acid residues in lipopolysaccharides of Salmonella minnesota rough mutants. European Journal of Biochemistry 131, 195-200.

BRADFORD, M. M. (1976). A rapid and sensitive method for the quantitation of microgram quantities of protein utilizing the principle of protein-dye binding. Analytical Biochemistry 72, 248-254.

Chaby, R. \& SzABo, L. (1975). 3-Deoxy-2-octulosonic acid 5-phosphate: a component of the endotoxin of Bordetella pertussis. European Journal of Biochemistry 59, 277-280.

Chapman, A. J., Adler, B. \& Faine, S. (1988). Antigens recognized by the human immune response to infection with Leptospira interrogans serovar hardjo. Journal of Medical Microbiology 25, 269-278.

Charon, D. \& Szabo, L. (1972). The synthesis of 3deoxy-5-O-methyloctulosonic acid and its behaviour in the Warren reaction. European Journal of Biochemistry 29, 184-187.

Chen, P. S. J., Toribara, T. Y. \& Warner, H. (1956). Microdetermination of phosphorus. Analytical Biochemistry 28, 1756-1758.

Cinco, M., Banfi, E. \& PANFili, E. (1986). Heterogeneity of lipopolysaccharide banding patterns in Leptospira spp. Journal of General Microbiology 132 , 1135-1138.

Cinco, M., Banfi, E., Giani, M., Gudelach, M. L. \& GalaNos, C. (1988). Chemical and biological properties of a phenol-water extract from Leptospira interrogans. Evidence for the absence of lipopolysaccharide. Infection 16, 238-241.
Drogue, W., Lehmann, V., Luderitz, O. \& WestPHAL, O. (1970). Structural investigations on the 2keto-3-deoxyoctonate region of lipopolysaccharides. European Journal of Biochemistry 14, 175-184.

Dubois, M., Gilles, K. A., Hamilton, J. K., Rebers, P. A. \& SMITH, F. (1956). Colorimetric method for determination of sugars and related substances. Analytical Chemistry 28, 350-356.

FAINE, S. (1982). Guidelines for the control of leptospirosis WHO Offset Publication, no. 67. Geneva: WHO.

Faine, S., Adler, B., Christopher, W. \& Valentine, R. (1984). Fatal congenital human leptospirosis. Zentralblatt für Bakteriologie, Mikrobiologie und Hygiene (Abteilung I, Originale A) 257, 548.

FARRELly, H. E., ADler, B. \& FAINE, S. (1987). Opsonic monoclonal antibodies against lipopolysaccharide antigens of Leptospira interrogans serovar hardjo. Journal of Medical Microbiology 23, 1-7.

Finco, D. R. \& Low, D. G. (1967). Endotoxic properties of Leptospira canicola. American Journal of Veterinary Research 28, 1863-1872.

Galanos, C. \& LUDERITZ, O. (1984). Lipopolysaccharide: properties of an amphipathic molecule. In Handbook of Endotoxin, vol. 1, pp. 46-58. Edited by E. T. Rietschel. Amsterdam: Elsevier Science Publishers.

HITCHCOCK, P. J. \& BRown, T. M. (1983). Morphological heterogeneity among Salmonella lipopolysaccharide chemotypes in silver-stained polyacrylamide gels. Journal of Bacteriology 154, 269-277.

IsOGaI, E., IsogaI, H., KuREbayashI, Y. \& ITo, N. (1986). Biological activities of leptospiral lipopolysaccharide. Zentralblatt für Bakteriologie, Mikrobiologie und Hygiene (Abteilung I, Originale A) 261, 53-64.

JANTZEN, E. \& BRYN, K. (1985). Whole-cell and lipopolysaccharide fatty acids and sugars of Gram negative bacteria. In Chemical Methods in Bacterial Systematics, pp. 145-171. Edited by M. Goodfellow and D. E. Minnikin. London: Academic Press.

Jessop, H. L., Demarco de Hormaeche, R., Senior, K. E. \& Tonks, P. (1988). Partitioning of gonococcal LPS into phenol and water: different LPS composition of in vivo and in vitro selected variants. FEMS Microbiology Letters 55, 207-212.

Jost, B. H., AdLeR, B., VINH, T. \& FAINe, S. (1986). A monoclonal antibody reacting with a determinant on leptospiral lipopolysaccharide protects guinea pigs against leptospirosis. Journal of Medical Microbiology 22, 269-275.

Jost, B. H., ADLER, B. \& FAINE, S. (1988). Reaction of 
monoclonal antibodies with species specific determinants in Leptospira interrogans outer envelope. Journal of Medical Microbiology 27, 51-57.

KhaRkHaNis, Y. D., ZeTter, J. Y., JaCkson, J. J. \& CARLO, D. S. (1978). New and improved microassay to determine 2-keto-3-deoxyoctonate in lipopolysaccharide of Gram negative bacteria. Analytical Biochemistry 85, 595-601.

KMETY, E. \& DikKen, H. (1988). Revised list of Leptospira serovars. 1. Alphabetical order. International Committee on Systematic Bacteriology of the International Union of Microbiological Societies. Subcommittee on the Taxonomy of Leptospira. Groningen: University Press.

Kreutzer, D. L., Buller, C. S. \& Robertson, D. C. (1979). Chemical characterization and biological properties of lipopolysaccharides isolated from smooth and rough strains of Brucella abortus. Infection and Immunity 23, 811-818.

LAEMMLI, U. K. (1970). Cleavage of structural proteins during the assembly of the head of bacteriophage T4. Nature, London 227, 680-685.

LefebVre, R. B. \& ThiermanN, A. B. (1986). DNA homology studies of leptospires of serogroups Sejroe and Pomona from cattle and swine. American Journal of Veterinary Research 47, 959-963.

Lefebvre, R. B., ThiermanN, A. B. \& Foley, J. (1987). Genetic and antigenic differences of serologically indistinguishable leptospires of serovar hardjo. Journal of Clinical Microbiology 25, 2094-2097.

LUderitz, O., GMeINER, J., KICKHOFER, B., MAYeR, H., WestPhal, O. \& Wheat, R. W. (1968). Identification of D-mannosamine and quinovosamine in Salmonella and related bacteria. Journal of Bacteriology 95, 490-494.

Moss, C. W., SAmuels, S. B., Liddle, I. \& McKinney, R. M. (1973). Occurrence of branched-chain hydroxy fatty acids in Pseudomonas maltophilia. Journal of Bacteriology 114, 1018-1024.

Nowotny, A. (1979). Basic Exercises in Immunochemistry: A Laboratory Manual. Berlin: SpringerVerlag.

RAFF, R. A. \& WhEAT, R. W. (1968). Carbohydrate composition of the phenol-soluble lipopolysaccharides of Citrobacter freundii. Journal of Bacteriology 95 , 2035-2043.

Rebers, P. A., Wessman, G. E. \& Robyt, J. F. (1986). A thin-layer-chromatographic method for analysis of amino sugars in polysaccharide hydrolysate. Carbohydrate Research 153, 132-135.

Robinson, A. J., Ramadass, P., Lee, A. \& Marshall, R. B. (1982). Differentiation of subtypes within Leptospira interrogans serovars hardjo, balcanica, and tarassovi, by restriction endonuclease DNA analysis (Brenda). Journal of Medical Microbiology 15, 331338.

Shabarova, Z. A., Buchanan, J. G. \& Baddiley, J. (1962). The composition of pneumococcus type specific substances containing phosphorus. Biochimica et biophysica acta 57, 146-148.

Shimizu, T., Matsusaka, E., Nagakura, N., Takayanagi, K., Masuzawa, T., Iwamoto, Y., MoRita, T., MifuchI, I. \& Yanagihara, Y. (1987a). Chemical properties of lipopolysaccharide-like substance (LLS) extracted from Leptospira interrogans serovar canicola strain Moulton. Microbiology and Immunology 31, 717-725.
Shimizu, T., Matsusaka, E., Nagakura, N., Takayanagi, K., Masuzawa, T., Iwamoto, Y., Morita, T., Mifuchi, I \& Yanagihara, Y. (1987b). Biological properties of lipopolysaccharide-like substance (LLS) extracted from Leptospira interrogans serovar canicola strain Moulton. Microbiology and Immunology 31, 727-735.

Shinagawa, M. \& Yanagawa, R. (1972). Isolation and characterization of a leptospiral type-specific antigen. Infection and Immunity 5, 12-19.

Stahl, E. (1969). Thin Layer Chromatography. A Laboratory Handbook. Berlin, Heidelberg \& New York: Springer-Verlag.

Terpstra, W. J., KoRver, H., SchOONe, G. J., Leeuwen, J. V., SchonemanN, C. E., De JongeAglibut, S. \& KolK, A. H. J. (1987). Comparative classification of Leptospira serovars of the pomona group by monoclonal antibodies and restrictionendonuclease analysis. Zentralblatt für Bakteriologie, Mikrobiologie und Hygiene (Abteilung I, Originale A) 266, 412-421.

ThIERMANN, A. B. (1984). Bovine leptospirosis : current developments and trends. Journal of American Veterinary Medicine Association 184, 722-725.

ThiermanN, A. B. \& Ellis, W. A. (1986). Identification of leptospires of veterinary importance by restriction endonuclease analysis. In The Present State of Leptospirosis Diagnosis and Control, pp. 91-104. Edited by W. A. Ellis and T. W. A. Little. The Netherlands: Martinus Nijhoff.

ThiermanN, A. B., Hansake, A. L., Foley, J. W., White, F. H. \& Kingscote, B. F. (1986). Reclassification of North American leptospiral isolates belonging to serogroups Mini and Sejroe by restriction endonuclease analysis. American Journal of Veterinary Research 47, 61-66.

TsaI, C. M. \& Frasch, C. E. (1982). A sensitive silver stain for detecting lipopolysaccharides in polyacrylamide gels. Analytical Biochemistry 119, 115-119.

VINH, T., FAINE, S. \& ADLER, B. (1984). Adhesion of leptospires to mouse fibroblasts (L929) and its enhancement by specific antibody. Journal of Medical Microbiology 18, 73-85.

VINH, T., Adler, B. \& FaINe, S. (1986a). Ultrastructure and chemical composition of lipopolysaccharide extracted from Leptospira interrogans serovar copenhageni. Journal of General Microbiology 132, 103-109.

VinH, T., Adler, B. \& FAINe, S. (1986b) Glycolipoprotein cytotoxin from Leptospira interrogans serovar copenhageni. Journal of General Microbiology 132, 111-123.

WESTPHAL, O. \& JANN, K. (1965). Bacterial lipopolysaccharides: extraction with phenol-water and further applications of the procedure. Methods in Carbohydrate Chemistry 5, 83-91.

White, F. H., Sutherland, G. E., Raynor, L. E., COTTREL, C. R. \& SUlZER, K. R. (1981). Leptospira interrogans serovars hardjo and pomona: causes of infections in diary cows and humans in Florida. Public Health Reports 96, 250-254.

Wilkinson, S. G., Galbraith, L. \& Lightfoot, G. A. (1973). Cell wall lipids and lipopolysaccharides of Pseudomonas species. European Journal of Biochemistry 33, 158-174.

WOLFF, J. W. (1953). The classification of pathogenic leptospires. In Symposium on the Leptospires, Medi- 
cal Sciences Publication no. 1. pp. 174-185. Washington, DC: US Government Publishing Office.

Wollenweber, H. V., Rietschel, E. T., Hofstad, T., Weinbrau, A \& Lindberg, A. A. (1980). Nature, type of linkage, quantity and absolute configuration of (3-hydroxy) fatty acids in lipopolysaccharide of Bacteroides fragilis NCTC 9343 and related strains. Journal of Bacteriology 144, 898-903

Yasuda, P. H., Steigerwalt, A. G., Sulzer, K. R., Kaufmann, A. F., Rogers, F. \& Brenner, D. J.
(1987). Deoxyribonucleic acid relatedness between serogroups and serovars in the family Leptospiraceae with proposals for seven new Leptospira species. International Journal of Systematic Bacteriology 37, 407-415.

ZAMZE, S. E. \& Moxon, E. R. (1987). Composition of lipopolysaccharides from different capsular serotype strains of Haemophilus influenzae. Journal of General Microbiology 133, 1443-1451. 